\title{
Aesthetic perception and psychological impact of molar-incisor hypomineralisation among patients and parents
}

\author{
Fernanda Mafei Felix da Silva ${ }^{1}$, Christiane Vasconcelos Cruz $^{1}$, Luise Leal ${ }^{1}$, Marcelo de Castro Costa ${ }^{1}$
}

${ }^{1}$ Department of Pediatric Dentistry and Orthodontics, School of Dentistry,

Universidade Federal do Rio de Janeiro, Rio de Janeiro, RJ, Brazil

\section{Abstract}

The aim this study was investigate's patient and parent's aesthetic perception and psychological impact of molar-incisor hypomineralisation (MIH) and to assess the correlation of $\mathrm{MIH}$ with caries experience. The sample comprised 56 children, 28 with $\mathrm{MIH}$ and 28 without $\mathrm{MIH}$ (comparison group), and their gardens $(n=56)$. For the perception data we used the Child and Parent's Questionnaire of Teeth Appearance. We used the European Academic of Paediatric Dentistry (EAPD) criteria to define MIH. Caries experience was assessed by Decayed, Missing and Filled Teeth (DMFT) index. Chi-square, Student's t-test and correlation tests were used with significance level set at $5 \%$. Most children were male $(n=35 ; 62.5 \%)$ and patients with MIH perceived their affected teeth as stainned $(p=0.01)$. MIH was considered by parents $(6.96 \pm 1.7)$ to enhance psychosocial condition (social, physical, and psychological social) of their children $(p<0.01)$. Patients with severe MIH showed the worst perception about the color of the teeth $(p=0.07)$. There was no correlation between DMFT scores and presence of MIH $(p=0.80)$. Patients and parents perceived MIH. Groups with severe MIH (children/ parents) showed the worse aesthetic perception.

\section{Introduction}

Molar incisor hypomineralisation (MIH) is defined as a qualitative enamel defect that occurs during amelogenesis [1,2]. Its aetiology has been linked to both environmental factors

(disturbances during pregnancy, severe infections, frequent use of antibiotics in childhood) and genetic factors (genetic variations in TUFT1, TUFT11, AMELX and ENAM) [3, 4-6]. The prevalence of this condition varies considerably in different parts of the world ranging from 2.4 to $40 \%$ in Europe $[7,8]$ and from $12.3 \%$ to $40.2 \%$ in Brazil $[9,10]$.

One of the main characteristics of $\mathrm{MIH}$ is enamel porosity and discoloration, which may vary from white to yellowish and brown [11]. It usually affects one or more permanent molars and/ or may the permanent incisors [10,12]. In most of the, MIH may cause loss of tooth structure, resulting in functional and aesthetic problems
Citation: Silva FMF, et al. (2019) Aesthetic perception and psychological impact of molarincisor hypomineralisation among patients and parents Dentistry 3000. 1:a001 doi: $10.5195 /$ d3000.2019.90 Received: November 26, 2018 Accepted: March 28, 2018 Published: July 25, 2019 Copyright: (C2019 Silva FMF, et al. This is an open access article licensed under a Creative Commons Attribution Work 4.0 United States License. Email:pttpo2009@yahoo.com.br for the individual, which may affect their quality of life $[13,14]$. There are few literature reports on the social impact of $\mathrm{MIH}$, especially in cases of changes in color and dental caries susceptibility $[14,15$, 16].

Over the years, aesthetic demands of the smile has been increasing worldwide, especially among children and adolescents [17, 18, 19]. However, it is difficult to measure the impact caused by changes in tooth enamel, since the 
aesthetic evaluation is subjective. Thus, the aims of this study were to determine children, parents' perceptions, and psychological impact of $\mathrm{MIH}$ before and after treatment to add to the relatively sparse literature. We also aimed to assess possible correlation between $\mathrm{MIH}$ and caries experience.

\section{Methods}

Study population

This study was performed after approval from the local Ethics Committee for Research (Hospital Universitário Clementino Fraga Filho - HUCFF/UFRJ - Number: 44598514.7.00005257).

subjects/guardians read and signed a written informed consent before their participation in the study. A convenience sample consisting in invidious of both sexes divided by children between 7 and 14 years old treated at Paediatric Dentistry Clinic of the Federal University of Rio de Janeiro and their parents.

The sample was divided into children with $\mathrm{MIH}(\mathrm{n}=28)$ and children without $\mathrm{MIH}(n=28)$ in treated at Paediatric Dentistry Clinic of the Federal University of Rio de Janeiro, and their parents $(n=56)$. The inclusion criteria for both groups were having permanent incisors, first permanent molars erupted, and in the MIH group, the permanent incisors had to be affected. The exclusion criteria for both groups included children with syndromes, dental trauma or the use of a fixed appliance.

The clinical examination was performed by one calibrated dentist (FMF) and was carried out with a mirror and a probe in the dental chair after dental prophylaxis using artificial light. Caries experience was assessed by the DMFT index $[20,21]$. MIH was evaluated using the EAPD criteria (European Academic of Paediatric Dentistry) [11,12]. Mild MIH cases was considered when the tooth presented demarcated opacity, without any loss of structure, while severe cases were considered when the teeth showed loss of structure past or current lesion requiring treatment or presence of atypical restorations were defined as having severe MIH [11].

To assess the intra examinerreliability, an exercise was previously applied by the examiner (S.FM) and in the gold standard (C.MC) evaluator with 20 clinical pictures of dental enamel defects (eight with $\mathrm{MIH}$ ). Two weeks after the first assessment, a new assessment was carried out by the examiner and the resulting kappa was 0.88 . At the end of the clinical examination, each patient and parents received oral hygiene instructions. In addition, the patients received a dental prophylaxis and a topical fluoride application

\section{Questionnaires}

A perception survey was carried out using The Child and Parent's
Questionnaire of Teeth Appearance [22]. This instrument has been validated and adapted to the Brazilian context [23] and represents a standard tool for estimating the impact of aesthetic perceptions of enamel opacities.

This instrument, has a version for children and adults, includes physical, psychological and social issues. In addition, questions about the dental color aspects, dental appearance, alignment and oral health.

The response options for the five questions and sub-items were presented in the form of multiplechoice items. Responses are grade ranging from best condition (0) to worst possible condition (4). The first three questions investigate how the child or her/his parent has felt over the past two months and whether he or she has felt uncomfortable, concerned or has been prevented from smiling because of the appearance of his or her teeth, according to the views of his or her parents/guardians and himself or herself.

An additional question with four subratings for the perception of children and their parents about appearance, position, colour and health of their teeth (or their children) was asked. The last item asked the interviewee about his/her opinion on satisfaction or dissatisfaction with the colour of the teeth, according to the following sentence: 'The colour of 
TABLE 1. CHARACTERISTICS OF THE SAMPLE

\begin{tabular}{|c|c|c|c|c|}
\hline & CHILDREN & MHI GROUP & $\begin{array}{l}\text { CONTROL } \\
\text { GROUP }\end{array}$ & $\begin{array}{c}P \\
\text { VALUE }\end{array}$ \\
\hline MEAN AGE (SD) & $9.39(2.04)$ & $9.43(1.91)$ & $9.36(2.19)$ & - \\
\hline Sex n (\%) & & & & 0.58 \\
\hline Female & $35(62.5)$ & 19(67.9) & $16(57.1)$ & \\
\hline Male & $21(37.5)$ & $9(32.1)$ & $12(42.9)$ & \\
\hline \multicolumn{5}{|l|}{ a CCEB n (\%) } \\
\hline B2 & $18(32.1)$ & $10(35.7)$ & $8(28.6)$ & \\
\hline C1 & $27(48.2)$ & $14(40)$ & $13(46.4)$ & \\
\hline $\mathrm{C2}$ & $8(14.3)$ & $3(10.7)$ & $5(17.9)$ & 0.77 \\
\hline D2 & $3(5.4)$ & $1(3.6)$ & $2(7.1)$ & \\
\hline \multirow[t]{2}{*}{ b DMFT X MIH } & $0.95( \pm 1.6)$ & $1.00( \pm 1.54)$ & $0.89( \pm 1.68)$ & 0.80 \\
\hline & - & - & - & \\
\hline $\begin{array}{l}\text { Brazilian economic } c \\
2<R \$ 895 \\
\text { orrelation test perforn } \\
\text { te: } \mathrm{P} \text { value was base }\end{array}$ & Shi Square & $\begin{array}{l}\text { B } \quad \mathrm{B} 2<\mathrm{R} \$ 3 \\
\text { and controls. } \\
\text { ). }\end{array}$ & 8, & \\
\hline
\end{tabular}

my teeth (or the tooth of my son) are nice and beautiful'.

Statistical analysis

Data were analysed using SPSS version 20.0 (Statistical Package for

Social Sciences, SPSS Inc., Chicago, III). Descriptive statistics was performed. A Shapiro-Wilks test was carried out to evaluate the pattern of sample distribution. Student's t-test and binary logistic regression were performed to
$39.3 \pm 7.4$ and most of children were male $(62.5 \% \mathrm{n}=35)$ (table 1$)$. In the groups with $\mathrm{MIH} \quad(\mathrm{n}=28)$ and control $(n=28)$ there was no difference $(p>0.05)$ between sex, ethnicity, socio-economic condition or dental caries experience (Table1).

Patients with $\mathrm{MIH}$ perceived their stained teeth $(p=0.01)$ (Table 2). There was no statistically significant difference between the two groups when comparing individuals with $\mathrm{MIH}(4.18 \pm 1.3)$ and the comparison group $(4.82 \pm 2.1)$ regarding physical, psychological and social conditions (Table 2). In addition, in the $\mathrm{MIH}$ parent group, a worse perception $(6.96 \pm 1.7)$ than the one in the comparison group (6.50 \pm 2.9$)$ was seen, which was statistically significant with regards to staining perception of teeth and to opinion about oral health $(p=0.01$ and $p=0.03$, respectively) (Table 2 ).

Perception between parents and children showed the former had a worse perception in both psychosocial conditions $(6.96 \pm 1.7)$ and appearance $(21,81 \pm 3.9)$ (Table $3)$. Regarding the severity of the MIH, 64.3\% ( $n=18)$ showed mild and $35.7 \%(n=10)$ showed severe $\mathrm{MIH}$. Patients with severe $\mathrm{MIH}$ $(4.80 \pm 1.2)$ and their parents $(7.5 \pm 2.0)$ showed the worst perception on physical, psychological and social conditions. In addition, children with severe $\mathrm{MIH}$ showed greater 
TABLE 2. Evaluation of agreement between parents/children (MIH and controls) for aesthetic perception and psychosocial conditions.

\begin{tabular}{|c|c|c|c|c|c|c|}
\hline & \multicolumn{2}{|c|}{ Subjects (children) } & \multirow[t]{2}{*}{$P$ value } & \multicolumn{2}{|c|}{ Parents } & \multirow[t]{2}{*}{$P$ value } \\
\hline & MIH group & Controls & & MIH group & Controls & \\
\hline $\begin{array}{l}\text { *PHYSICAL, } \\
\text { PSYCHOLOGICAL, } \\
\text { AND SOCIAL } \\
\text { CONDITIONS }\end{array}$ & $4.18( \pm 1.3)$ & $4.82( \pm 2.1)$ & 0.17 & $6.97( \pm 1.7)$ & $6.50( \pm 2.9)$ & ** \\
\hline $\begin{array}{l}\text { CONCERNS WITH } \\
\text { TOOTH POSITION }\end{array}$ & $2.75( \pm 1.37)$ & $2.96( \pm 1.73)$ & 0.61 & $3.29( \pm 1.4)$ & $2.93( \pm 1.5)$ & 0.73 \\
\hline TOOTH CONDITION & $2.54( \pm 1.20)$ & $2.24( \pm 1.73)$ & 0.22 & $2.68( \pm 1.0)$ & $2.75( \pm 1.4)$ & 0.04 \\
\hline $\begin{array}{c}\text { STAINING } \\
\text { PERCEPTION TEETH }\end{array}$ & $2.75( \pm 1.04)$ & $2.07( \pm 0.85)$ & 0.01 & $3.21( \pm 0.83)$ & $2.64( \pm 1)$ & 0.01 \\
\hline $\begin{array}{l}\text { ORAL HEALTH } \\
\text { OPINION }\end{array}$ & $2.0( \pm 1.12)$ & $1.71( \pm 1.08)$ & 0.33 & $2.71( \pm 1.0)$ & $2.04( \pm 1.2)$ & 0.03 \\
\hline $\begin{array}{c}\text { SATISFACTION WITH } \\
\text { THE COLOUR OF THE } \\
\text { TOOTH }\end{array}$ & $2.64( \pm 1.2)$ & $2.24( \pm 1.0)$ & 1.00 & $3.61( \pm 0.95)$ & $3.14( \pm 1.1)$ & 0.10 \\
\hline
\end{tabular}

*The sum of the first three questions: Discomfort with appearance of their teeth, Concern about the appearance of the teeth and Discomfort with smile, was assed by Student's t-test $(\mathrm{p}<0.05)$.

dissatisfaction with tooth Physical, psychological and social coloration. (Table 4).

\section{Discussion}

Aesthetic alterations in dental enamel may have a significant impact on the physical, social and psychological well-being of individuals and also affect their families $[24,25]$. MIH may be considered as

an impacting enamel disturbance because it highly affects aesthetic and function. Moreover, in the most severe cases, it may lead to loss of structure and dental sensitivity as well as an increase in caries experience $[26,27]$. conditions related to children and their parents were perceived in the present study and may affect their quality of life. Furthermore, the appearance of $\mathrm{MIH}$ teeth (displayed as the perception of teeth being stained) was perceived by and influenced both children and parents. According to a study, the most severe enamel defects were related to aesthetic complaints by the patients and sometimes required aesthetic restorative treatment [14].

In relation to tooth alignment (tooth position), this was perceived by both children and parents in the control group. This leads us to support that the position of the teeth can also be related to a negative impact on perception of the smile aesthetics. This study showed that parents were more concerned than children with regard to dental appearance, colour of teeth and tooth alignment [19].

Regarding dental caries in the present study, there was no statistically significant association between $\mathrm{MIH}$ and dental caries, although other studies related to MIH showed increased caries susceptibility in $\mathrm{MIH}$ patients $[26,27]$. In this context, we can 
TABLE 3. Comparison of aesthetic perceptions between children and parents with MIH and controls.

\begin{tabular}{|c|c|c|c|c|c|}
\hline & \multicolumn{2}{|c|}{$\mathrm{MIH}$} & \multicolumn{2}{|c|}{ Controls } & \multirow{3}{*}{$\begin{array}{c}\mathrm{P}- \\
\text { value }\end{array}$} \\
\hline & Children & Parents & Children & Parents & \\
\hline & $n=28$ & $n=28$ & $n=28$ & $n=28$ & \\
\hline $\begin{array}{l}\text { *Physical, } \\
\text { psychologi } \\
\text { cal, and } \\
\text { social } \\
\text { conditions }\end{array}$ & $4.18( \pm 1.3)$ & $6.96( \pm 1.7)$ & $4.82( \pm 2.1)$ & $6.50( \pm 2.9)$ & 0.03 \\
\hline $\begin{array}{c}{ }^{* *} \text { Aesthetic } \\
\text { perception } \\
\text { of } \\
\text { position, } \\
\text { staining, } \\
\text { oral, } \\
\text { health and } \\
\text { satisfactio } \\
\mathbf{n} \text { with the } \\
\text { colour of } \\
\text { the teeth }\end{array}$ & $20.25( \pm 3.7)$ & $25.07(3.7)$ & $20.11( \pm 5.1)$ & $22.86(2.0)$ & 0.03 \\
\hline
\end{tabular}

Note: P-value was assessed by Student's t-test $(p<0.05)$ comparing children and parents. *The sum of the first three questions: Discomfort with appearance of their teeth, Concern about the appearance of the teeth and Discomfort with smile. ${ }^{* *}$ The sum of additional question with four sub-ratings of the perception and last question of satisfaction with the colour of the tooth.

suppose that the severity of MIH may be related to caries experience, since in this study, mild MIH was predominant. It is noteworthy that some studies reported that even $\mathrm{MIH}$ patients with lower dental caries activity needed to be carefully monitored. This is because the teeth affected with $\mathrm{MIH}$ present more porous enamel, leading to fractures, facilitating accumulation of the biofilm [28].

In our study, all patients received oral hygiene instructions, fluoride application and restorative treatment, if necessary. Children with $\mathrm{MIH}$ received treatments ranging from preventive care (application of sealants and fluoride varnish) to restorations. The majority of treated teeth were at the severe level and most of them were first permanent molars. Some studies have shown that regardless of the affected tooth or locality, patients with enamel defects after treatment have a better perception of their quality of life [12].

As limitations, we can mention the child's age. This may have an influence on perception, because the sample was patients less than 14 years old. Age could hamper the understanding of the questions because the older the children, the higher the aesthetic concerns. Furthermore, caries experience (DMFT scores) tends to increase with age, but we do not think that age influenced our results since the $\mathrm{MIH}$ group and controls presented a similar mean age. This study demonstrated that children and their parents had the knowledge about the existence of the $\mathrm{MIH}$, in which may affected their quality of life, supposing that color alteration can influence the negative perception in the patient.

We suggest that other studies about the aesthetic perception among individuals with $\mathrm{MIH}$ will be performed by group of teenagers or adults who have a higher level of aesthetic requirements. Also, assess the actual need for aesthetic treatment in patients with $\mathrm{MIH}$ affecting incisors without a loss of structure.

\section{Conclusion}

MIH was perceived by both patients and parents as affecting physical, psychological or social 
TABLE 4. Evaluation of agreement between parents/children (MIH group) for aesthetic perception and psychosocial conditions accord into level of severity.

\section{GROUPS WITH MIH}

\begin{tabular}{|c|c|c|c|c|c|c|}
\hline & \multicolumn{2}{|c|}{ Children } & \multicolumn{4}{|c|}{ Parents } \\
\hline & Mild & Severe & $P$ value & Mild & Severe & $P$ value \\
\hline $\begin{array}{l}{ }^{*} \text { PHYSICAL, } \\
\text { PSYCHOLOGICAL, } \\
\text { AND SOCIAL } \\
\text { CONDITIONS }\end{array}$ & $3.94( \pm 1.24)$ & $4.55( \pm 1.30)$ & 0.23 & $6.9( \pm 1.32)$ & $7.5( \pm 2.30)$ & 0.90 \\
\hline $\begin{array}{l}\text { CONCERNS WITH } \\
\text { TOOTH POSITION }\end{array}$ & $2.35( \pm 1.27)$ & $3.36( \pm 1.36)$ & 0.60 & $3.29( \pm 1.36)$ & $3.27( \pm 1.68)$ & 0.97 \\
\hline TOOTH CONDITION & $2.65( \pm 1.17)$ & $2.36( \pm 1.36)$ & 0.56 & $2.88( \pm 1.11)$ & $2.36( \pm 0.81)$ & 0.19 \\
\hline $\begin{array}{c}\text { STAINING } \\
\text { PERCEPTION TEETH }\end{array}$ & $2.71( \pm 0.85)$ & $2.82( \pm 1.33)$ & 0.79 & $3.29( \pm 0.84)$ & $3.09( \pm 8.3)$ & 0.54 \\
\hline $\begin{array}{l}\text { ORAL HEALTH } \\
\text { OPINION }\end{array}$ & $2.06( \pm 0.97)$ & $1.91( \pm 1.38)$ & 0.74 & $2.82( \pm 1.19)$ & $2.55( \pm 0.93)$ & 0.52 \\
\hline $\begin{array}{c}\text { SATISFACTION WITH } \\
\text { THE COLOUR OF THE } \\
\text { TOOTH }\end{array}$ & $2.09( \pm 1.30)$ & $3.0( \pm 1.17)$ & 0.07 & $3.65( \pm 0.10)$ & $3.55( \pm 0.93)$ & 0.80 \\
\hline
\end{tabular}

*The sum of the first three questions: Discomfort with appearance of their teeth, Concern about the appearance of the teeth and Discomfort with smile". $P$-value assessed by Student's $t$-test $(p<0.05)$

features, and parents showed worse perception scores than children. Caries experience was not correlated to $\mathrm{MIH}$ in this sample.

\section{Acknowledgements}

This study was financed in part by the Coordenação de Aperfeiçonamento Pessoal de Nivel Superior Brasil- (CAPES) -
This study is part of the Masters Dissertation of the first author.

\section{References}

1. Developmental defects of enamel-historical and present-day perspectives of their pathogenesis. Suckiling GW. Advances in Dental Research 1989; 3(2): 87-94.
2. Clinical diagnosis of enamel defects: pitfalls and practical guidelines. Seow WK. International Dental Journal 1997; 47(3): 17382.

3. Amoxicilin may cause molar incisor hypomineralization. Laisi $S$, Ess A, Sahlberg C, Arvio P, LuKinma PL, Alaluusua S. J Dent Res 2009; 88: 132-136. 
4. Clinical E. molecular analysis of the enamelin gene ENAM in Colombian families with autosomal dominant amelogenesis imperfecta. Gutierrez S, Torres D, Bricen o I, Go 'mez AM, Baquero. Genetics and Molecular Biology 2012; 35(3): 557-66.

5. Genes expressed in dental enamel development are associated with molar-incisor hypomineralization. Jeremias $F$, Koruyucu M, Kuchler CE, Bayram M, Tuna BE, Deeley K, Pierri A, Souza J, Fragelli MB, Paschoal $A B$, Koray GF, Seymen MS, Caminaga LP, Vieira AR. Archives of Oral Biology 2013; 58: 1434-1442 a.

6. Aetilogy of Molar-Incisor Hypomineralization: A systematic review. Alaluusua S. European Archives of Paediatric Dentistry 2010; 11(2): 53-8.

7. Prevalence and diagnosis of molar-incisor hypomineralisation (MIH): a systematic review. Jälevik B. Eur Arch Paediatr Dent 2010; 11: 59-6.

8. Prevalence and distribution of demarcated opacities in permanent 1st molars and incisors in 6 to 8 year-old-Danish children. Wogelius P, Haubek D, Poulsen S. Acta Odontol Scand 2008; 66: 5864.

9. Prevalence and distribution of demarcated opacities and their squeals in permanent first molars and incisor in 7 to 13-year-old Brazilian children. Soviero $\mathrm{V}$, Haubek D, Trindade C, Matta T,
Poulsen S. Acta Odontol Scand 2009; 66: 170-175.

10. Molar incisor hypomineralization: prevalence severity and clinical consequences in Brazilian children Da Costa Silva CM, Jeremias F, Souza JF, Cordeiro $R C L$, Santos Pinto L, Zuanon ACC. Int J Paediatr Dent 2010; 20(6): 426-34.

11. Best clinical practice guidance for clinicians dealing with children presenting with Molar-IncisorHypomineralisation (MIH): An EAPD Policy Document. Lygidakis NA, Wong $F$, Jälevik $B$, Vierrou AM, Alaluusua S, Espelid I. Eur Arch Paediatr Dent 2010; 11(2): 75-81.

12. Judgement criteria for molar incisor hypomineralisation ( $\mathrm{MIH}$ ) in epidemiologic studies: a summary of the European meeting on $\mathrm{MIH}$ held in Athens, 2003 Weerheieijm $\mathrm{KL}$, Duggal $\mathrm{M}$, Majáre I, Papagiannoulis L, Koch G, Martens HC, et al.. Eur J Paediatr Dent 2003; 4: 110-3.

13. Dental enamel formation and its impact on clinical dentistry. Simmer JP, Hu JCC. Journal of Dental Education 2001; 65(9): 896905

14. Meneghim MC, Kozlowskl FC, Antonio C,Pereira A V. Assaf, Tagliaferro PS. International Journal of Paediatric Dentistry 2007; 17: 205-210.

15. Perception of dental fluorosis and other oral health disorders by 12-year-old Brazilian children.
Jeremias F, Souza JFD, Costa Silva CMD, Cordeiro RDCL, Zuanon ACC, Santos-Pinto L. Dental carie experience and Molar-Incisor Hypomineralization. Acta Odontol Scand 2013; 71: 17 b.

16. Clinical studies on molarincisor hypomineralisation part 2: development of a severity index. Chawla N, Messer LB, Silva M. Eur Arch Paediatr Dent 2008; 9: 191-9.

17. Clinical evaluation of desensitizing treatment for incisor teeth affected by Molar-Incisor Hypomineralization Ozgül BM, Saat S, Sönmez H, Oz FT.. J Clin Pediatr Dent 2013; 38(2): 101-5.

18. Aesthetic concerns of children and parents in relation to different classifications of the Tooth Surface Index of Fluorosis. Clark DC, Hann HJ, Williamson MF, Berkowitz J. Community Dent Oral Epidemiol 1993; 21: 360-364.

19.Comparison of dental esthetic perception of young adolescents and their parents. Kavand G, Broffitt B, Levy SM, Warren JJ J Public Health Dent 2012; 72(2): 164-71.

20. W.H.O. World Health Organization. Oral health surveys. Basic methods. Geneva: World Health Organization; 1997.

21. Sex differences in dental caries experience of elementary school children. Klein, H., Palmer, C. E. Studies on dental caries. VII. Publ HIth Rep 1938; 53(38):1685-1690. 
22. Development of a questionnaire to measure perceptions of, and concerns derived from, dental fluorosis. Martínez-Mier EA, Maupomé G, Soto-Rojas AE, Ureña-Cirett JL, Katz BP, Stookey GK. Community Dent Health 2004; 21(4): 299-305.

23. Percepção da fluorose dentária e avaliação da concordância entre relatos de pais e filhos: validação de um instrumento. Furtado GES, Sousa MLR, Barbosa TS, Wada RS, Martínez-Mier EA, Almeida MEL. Cad Saude Publica. 2012 Ago;28 (8):1493-505.

24. Esthetic perception and psychosocial impact of developmental and enamel defects among Malaysian adolescents. Sujak SL, Abdul Karim A, Dom TN. J Oral Sci 2004; 46(4): 221-6.

25. Seeking children's perspectives in the management of visible enamel defects. Abdul-Karim A, Yesudian G, O'Mahony J, Marshman Z. Int Paediatr Dent 2011: 21(2): 89-95.

26. Increase in severity of molarincisor hypomineralization and its relationship with the colour of enamel opacity: prospective cohort study. Da Costa-Silva CM, Ambrosano GM, Jeremias F, De Souza JF, Mialhe FL. Int J Paediatr Dent 2011; 21(5): 333-41.

$27 . \quad$ Molar incisor hypomineralization in Bosnia and Herzegovina: aetiology and clinical consequences in medium caries activity population. Muratbegovic
A, Markovic N, Gannibegovic Selimovic M. Eur Arch Paediatr Dent 2007; 8(4): 189-94.

28. Nonfluoride hypomineralizations in the permanent first molars and their impact on treatment need. Lepäniemi A, Lukinmaa PL, Alaluusua S. Caries Res. 2001; 35(1): 36-40.1 